\title{
Mesenchymal Stem Cells Enhance Vascular Endothelial Growth Factor-A, Endothelial Nitric Oxide Synthetase, and HSP70 Expression in Improving Erectile Dysfunction in Streptozotocin- induced Diabetic Rats
}

\begin{abstract}
Ade Indra Mukti ${ }^{1}$, Syafruddin $\|_{y a s}^{2}$ (D), Syah Mirsya Warli ${ }^{3}$, Agung Putra ${ }^{4,5,6 *}$, Nur Rasyid ${ }^{7}$ (D), Delfitri Munir ${ }^{1,8,9}$ (D), Kamal Basri Siregar ${ }^{10} \mathbb{D}$, Muhammad Ichwan ${ }^{11} \mathbb{D}$, Iffan Alif ${ }^{4}$, Nurul Hidayah ${ }^{4} \mathbb{D}$

${ }^{1}$ Department of Doctoral Degree Program, Faculty of Medicine, Universitas Sumatera Utara, Medan, Indonesia; ${ }^{2}$ Department of Biology, Faculty of Mathematics and Natural Sciences, Universitas Sumatera Utara, Medan, Indonesia; ${ }^{3}$ Department of Urology, Faculty of Medicine, Universitas Sumatera Utara Hospital, Medan, Indonesia; ${ }^{4}$ Stem Cell and Cancer Research, Faculty of Medical, Sultan Agung Islamic University, Semarang, Indonesia; ${ }^{5}$ Department of Pathology, Medical Faculty, Sultan Agung Islamic University, Semarang, Indonesia; ${ }^{6}$ Department of Postgraduate Biomedical Science, Medical Faculty, Sultan Agung Islamic University, Semarang, Indonesia; ${ }^{7}$ Department of Urology, Faculty of Medicine, Universitas Indonesia, Cipto Mangunkusumo General Hospital, Jakarta, Indonesia; ${ }^{8}$ Department of Otorhinolaryngology, Head and Neck Surgery, Faculty of Medicine, Universitas Sumatera Utara, Medan, Indonesia; ${ }^{9}$ Pusat Unggulan IPTEK Tissue Engineering, Universitas Sumatera Utara, Medan, Indonesia; ${ }^{10}$ Department of Oncology Surgery, Faculty of Medicine, Universitas Sumatera Utara, Universitas Sumatera Utara Hospital, Medan, Indonesia; ${ }^{11}$ Department of Pharmacology and Therapeutics, Faculty of Medicine, Universitas Sumatera Utara, Medan, Indonesia
\end{abstract}

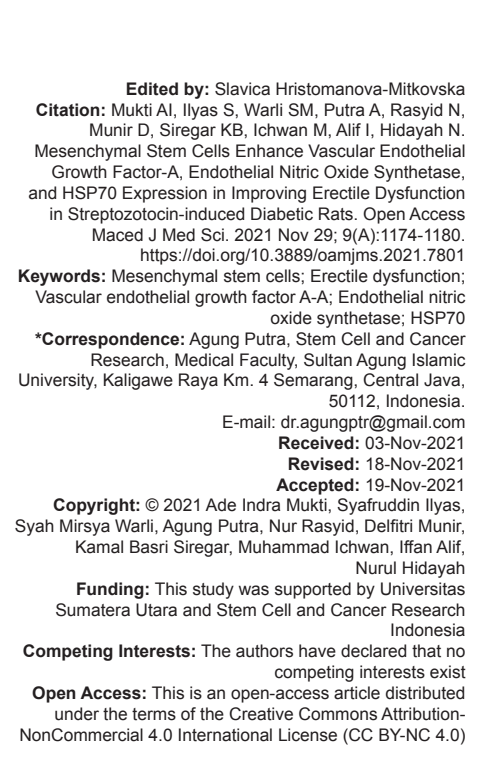

Abstract

AIM: This study investigated the therapeutic role of mesenchymal stem cells (MSCs) on erectile function in a diabetes mellitus erectile dysfunction (DMED) rat model by analyzing the expression of endothelial nitric oxide synthetase (eNOS), vascular endothelial growth factor A (VEGF-A), and the 70 kilodalton heat shock proteins (HSP70).

METHODS: MSCs were isolated from umbilical cords (UCs), and their characteristics identified by flow cytometry and osteogenic differentiation analysis. Thirty 8-week-old rats were divided into four groups: Sham, control, T1, and T2. After a $16 \mathrm{~h}$ fast, 24 rats were randomly selected and intraperitoneally injected with streptozotocin (STZ) to induce diabetes mellitus. At 8 weeks after STZ injection, rats with DMED were classified into four groups, sham, control group (DMED rats received $500 \mu \mathrm{L}$ phosphate buffer saline [PBS]); T1 (DMED rats treated with $500 \mu \mathrm{L}$ PBS containing $1 \times 106$ UC-MSCs); and T2 (DMED rats treated with $500 \mu \mathrm{L}$ PBS containing $2 \times 106 \mathrm{UC}-\mathrm{MSCs}$ ). Eight weeks after MSCs administration, the rats' erectile function was measured by cavernous nerve stimulation. The blinded histological and gene expression assessment were used to analyze the eNOS, HSP70 content, and VEGF-A expression on the penile tissues.

RESULTS: MSCs administration, rats in T1 and T2 groups showed a significant enhancement of erectile response that showed a trend of increase of VEGF-A mRNA level expression was $2.2 \pm 0.61$ in T2 Group supported with the optimum recovery of eNOS, in which the value of eNOS expression was $20.66 \% \pm 2.32 \%$. While optimum decrease of HSP70 content, the value of HSP70 expression was $15.50 \% \pm 0.90 \%$. IHC results showed that the DMED induction in rats caused a significant decrease of eNOS content in corpus cavernosum tissue.

CONCLUSION: MSCs could ameliorate DMED in rats by increasing VEGF-A and decreasing HSP70 and eNOS indicating these cells offer a potential application for DMED patients' treatment.

\section{Introduction}

Erectile dysfunction (ED) is a more prevalent diabetes mellitus (DM) complication, affecting up to $85 \%$ of male DM patients [1], [2], [3]. DM-induced erectile dysfunction (DMED) is more severe and commonly appears as ED in nondiabetic patients [4], [5]. The endothelial injury, decrease of smooth muscle content, neuropathy, and fibrosis are responsible for DMED [6]. Selective phosphodiesterase type-5 inhibitors (PDE5i) constitute the first-line agent for ED; however, it has much lower efficacy in treating patients with DMED [6], [7]. In this condition, revealing the novel alternative approach is a major needed to ameliorate DMED development. Over the past years, stem cell transplantation was considered a potential alternative strategy due to its capability to regulate the inflammatory milieu and recover the functional cells and tissues [8]. 
Umbilical cord-derived mesenchymal stem cells (UC-MSCs) are ubiquitous fibroblast-like-multipotent stromal cells that attract considerable interest because they can be easily isolated and abundantly assessed from the UC tissues through standardized procedures and have low immunogenicity potential [9], [10]. These cells could be described by high surface antigens levels, such as CD90, CD105, CD73, CD29, and low levels of CD31, CD34, CD45, CD14, CD11b, and HLA-DR [11], [12]. They can differentiate into specific cell lineages, including osteocytes, adipocytes, chondrocytes, and neurons [13]. Other terrific potencies of UC-MSCs are the immunomodulatory and regeneration properties through secreting various trophic factors [14]. The previous studies revealed that MSCs could induce endothelial nitric oxide synthetase (eNOS) [15], which has a beneficial function in maintaining the erectile function, suggesting that MSCs could be a promising strategy to treat DMED.

eNOS is a nitric oxide synthase (NOS) isoform which can produce nitric oxide (NO) continuously through short-term calcium-dependent [15]. Moreover, the expression of eNOS occurs in response to several molecules, including vascular endothelial growth factor A(VEGF-A) [16]. A recent study revealed that the DMED pathogenesis is due to an interfered NO secretion, in which eNOS has a major role in inhibiting the profibrotic consequences of hyperglycemia in penile tissues [6]. Another study revealed several vascular injuries, such as vascular smooth muscle and endothelial cell damage in the corpus cavernosum of DMED patients [8]. The sufficient VEGF-A is the main factor in improving vascular repair [17]. This condition could improve cellular repair characterized by decreased levels of cellular stress, characterized by the expression of The $70 \mathrm{kD}$ heat shock proteins (HSP70) [18]. Moreover, other studies have revealed the capability of MSCs in releasing VEGF-A to restore vascular tissues injury [16], [19], [20]. However, more impressive explanations regarding the high expression of VEGF-A and the mechanisms of MSCs in upregulating VEGF-A expression in injured tissues remain unclear.

This study builds a condition of streptozotocin (STZ)-induced DMED in the rat model. We evaluated the underlying mechanism of MSCs in improving the erectile function of DMED rats by analyzing the expression of eNOS, VEGF-A, and HSP-70.

\section{Materials and Methods}

\section{Animals and ethical statement}

Animal models complied with regulations of the Ethical Committee of the Faculty of Medicine, Universitas Sumatera Utara. The Ethical Committee approved this study (number 370/KEP/USU/2020). A total of thirty male Sprague-Dawley rats (8 weeks- old) weighting 200-250 g were purchased from Lembaga Penelitian dan Pengujian Terpadu, Unit IV, Universitas Gadjah Mada. After a $16 \mathrm{~h}$ fast, 24 rats were randomly selected and intraperitoneally injected with (STZ, $60 \mathrm{mg} / \mathrm{kg}$, Sigma-Aldrich, St. Louis, MO, USA). The remaining six rats were used as sham (rats with no DMED received $500 \mu \mathrm{L}$ phosphate buffer saline [PBS]).

\section{Assessment of rats' blood glucose and body weight}

The blood glucose levels and body weights of rats were analyzed at the beginning and end of treatment. The blood glucose level was measured by a pharmaceutical-grade glucometer (Accu-Check; Roche, Basel, Switzerland). For DM validation, the blood glucose was measured on the $3^{\text {rd }}$ day after STZ induction. Of the 24 rats, 21 (87.50\%) were diabetic with higher than $300 \mathrm{mg} / \mathrm{dl}$ fasting glucose levels.

\section{Assessment of ED}

At 8 weeks after STZ injection, apomorphine (APO, 100 g/kg; Sigma-Aldrich, St. Louis, MO, USA) was used to select the ED of rats according to Heaton's method [21]. Rats with DMED were present in 18 of the $21(85.71 \%)$ and identified by unresponsive erectile stimulation within $30 \mathrm{~min}$.

\section{Administration of MSC's}

Four weeks after DMED were induced, 24 rats were randomly assigned into four groups (six rats in each group): Sham (placebo or no treatment group); control (DMED rats received $500 \mu \mathrm{L}$ PBS); T1 (DMED rats treated with $500 \mu \mathrm{L}$ PBS containing $1 \times 10^{6} \mathrm{UC}-\mathrm{MSCs}$ ); and T2 (DMED rats treated with $500 \mu \mathrm{L}$ PBS containing $2 \times 10^{6}$ UC-MSCs). MSC intervention with a $25 \mathrm{G}$ needle was carried out at week 8 (after validation) with a saline volume of $300 \mu \mathrm{L}$. All rats received low-dose anesthesia before receiving the intracavernous injection. MSCs were injected 1 time for 4 weeks intracavernous which was divided right and left in the corpus cavernosum to spread throughout the tissue. Then the rats were reared until week 12. ED validation was also carried out before the rats were sacrificed to analyze the changes before and after treatment.

\section{UC-MSCs isolation and culture}

UCs were collected from 19-day pregnant female rats, and the MSCs were isolated and cultured according to previous standardized methods [10]. In brief, UC tissue was cut into smaller pieces under aseptic conditions. A UC tissue section was planted 
into a culture flask containing Dulbecco's Modified Eagle Medium (DMEM) (Sigma-Aldrich, Louis St, MO), supported with $1 \%$ penicillin $(100 \mathrm{U} / \mathrm{mL}) /$ streptomycin $(100 \mu \mathrm{g} / \mathrm{mL})\left(\mathrm{Gibco}^{\mathrm{TM}}\right.$ Invitrogen, NY, USA), 0.25\% amphotericin B (Gibco ${ }^{\mathrm{TM}}$ Invitrogen, NY, USA), 10\% fetal bovine serum (FBS) (Gibco ${ }^{\mathrm{TM}}$ Invitrogen, NY, USA), and cultured at $37^{\circ} \mathrm{C}$ in a humidified atmosphere consisting $5 \% \mathrm{CO}_{2}$. The culture medium was replaced every 3 days. After reaching approximately $80 \%$ confluence, UC-MSCs-like in culture flasks was passage into a new culture flask. UC-MSCs-like at passage 4 was used for further studies.

\section{Flow cytometry}

UC-MSCs-like membrane antigens at passage 4 were characterized using flow cytometry. Briefly, after UC-MSCs were passaged and washed, the cells were stained for 30 min using PBS containing anti-CD90.1-PerCP (cat. \# 557266; BD, San Diego, CA, USA), anti-CD29-alexa fluor 647 (cat. \# 562153; BD, San Diego, CA, USA), anti-CD45-FITC (cat. \# 554877; BD, San Diego, CA, USA), and anti-CD31-PE (cat. \# 555027; BD, San Diego, CA, USA) in the dark at room temperature. The cells were then rinsed twice using PBS. The flow cytometry and post-acquisition analysis were performed and calculated by a BD Accuri C6 Plus flow cytometer (BD, San Diego, CA, USA) and BD Accuri C6 Plus software (BD, San Diego, CA, USA).

\section{Differentiation of UC-MSCs}

We further performed the osteogenic differentiation of UC-MSCs-like in passage 4. The UC-MSCs-like were expanded in standard medium containing DMEM that augmented with $10 \%$ FBS, $1 \%$ penicillin/streptomycin (100 U/mL; respectively) and $0.25 \%$ amphotericin $\mathrm{B}(62.5 \mu \mathrm{g} / \mathrm{mL})$ at $37^{\circ} \mathrm{C}, 5 \% \mathrm{CO}_{2}$ and humidified atmosphere until $95 \%$ confluency. An osteogenic differentiation medium made of MesenCult ${ }^{\mathrm{TM}}$ osteogenic basal medium (Rat) (cat. \# 05505; Stem Cell Technologies, Singapore) augmented with $20 \%$ MesenCult ${ }^{\mathrm{TM}}$ Osteogenic Stimulatory Supplement (Rat) (cat \# 05506; Stem Cell Technologies), 1\% L-Glutamine (Gibco $^{\mathrm{TM}}$ Invitrogen), 1\% penicillin/streptomycin (100 $\mathrm{U} / \mathrm{mL}$; respectively) (Gibco ${ }^{\mathrm{TM}}$ Invitrogen), and $0.25 \%$ amphotericin B (62.5 $\mu \mathrm{g} / \mathrm{mL})$ (Gibco ${ }^{\mathrm{TM}}$ Invitrogen), was a standard medium substitute. This osteogenic medium was replaced every 3 days. Alizarin red staining was performed followed by 21 days of osteogenic induction of MSCs (Sigma-Aldrich, Louis St, MO). The deposition of calcium was appeared in red color.

On the other side, for inducing adipogenic differentiation, the UC-MSCs-like with $95 \%$ confluency was cultured using adipogenic differentiation medium which made of MesenCult ${ }^{\mathrm{TM}}$ MSC Basal Medium (Rat) (cat \# 05505; Stem Cell Technologies), MesenCult ${ }^{\mathrm{TM}}$
Adipogenic Differentiation Supplement (Rat) (cat \# 05509; Stem Cell Technologies), 1\% L-Glutamine (Gibco $^{\text {TM }}$ Invitrogen), 1\% penicillin/streptomycin (100 $\mathrm{U} / \mathrm{mL}$; respectively) (Gibco ${ }^{\mathrm{TM}}$ Invitrogen), and $0.25 \%$ amphotericin B $(62.5 \mu \mathrm{g} / \mathrm{mL})$ (Gibco ${ }^{\mathrm{TM}}$ Invitrogen). The medium was changed every 3 days. After 14 days of adipogenic induction, the oil red staining was poured into cultured plates. The lipid deposition was shown in red color.

\section{Immunostaining analysis}

Six rats from each group receiving $80 \mathrm{mg} / \mathrm{kg}$ ketamine and $5 \mathrm{mg} / \mathrm{kg}$ xylazine were sacrificed after treatments. Half of the penile tissues were fixed in $4 \%$ paraformaldehyde in PBS for $24 \mathrm{~h}$ at $4^{\circ} \mathrm{C}$. Penile tissue slices were deparaffinized in xylene and rehydrated using sequential ethanol (100\%, 95\%, 80\%, 70\%, and $50 \%$ ). Peroxidase blocking activity was employed by $3 \% \mathrm{H}_{2} \mathrm{O}_{2}$ incubation. The tissues were incubated by following antibodies, such as anti-rabbit-eNOS polyclonal antibody (dilution 1:100, Cat. FNab10162, Fine Test, Wuhan, China) and anti-rabbit-HSP-70 polyclonal antibody (dilution 1:100, Cat. A12948, ABclonal, Wuhan, China) overnight at $4^{\circ} \mathrm{C}$. Secondary antibody staining was performed using biotinylated anti-rabbit IgG (Ref. STU700L10, Biocare Medical, CA, USA) at room temperature for $2 \mathrm{~h}$. The semiquantitative data analysis was employed using ImagePro Plus software (Media cybernetics, Inc.).

\section{VEGF-A relative expression analysis}

After thawing the frozen $100 \mathrm{mg}$ penile tissues, RNA was later extracted. TRI-Reagent (SigmaAldrich, Dorset, UK) was carried out to extract total RNA according to the instructions given, as used in our previous study [21]. The RNA sample was incubated by DNase I (Sigma-Aldrich, Dorset, UK) to abolish DNA contamination. Reverse transcription was performed with the Enhanced Avian First Strand cDNA Synthesis Kit (Sigma-Aldrich, Dorset, UK) per the manufacturer's instructions. The oligo $d[T]$ primer was used for reverse transcription, and the sample reaction mix was incubated at $70^{\circ} \mathrm{C}$ for $10 \mathrm{~min}$ and at $45^{\circ} \mathrm{C}$ for $30 \mathrm{~min}$. The polymerase chain reaction (PCR) for CDNA synthesis was employed using eco real-time PCR system (Illumina Inc., San Diego CA, USA).

VEGF-A and beta-actin as housekeeping gene was performed by KAPA SYBR® FAST Universal Kit (Sigma-Aldrich, Dorset, UK) using each oligonucleotide primer (VEGF-A forward 5'-CTGCTGTGTTGGGTGCACTGG-3' and VEGF-A reverse 5'-GGTTTGATCCGCATAATGTGCAT-3'; betaactin forward 5'-ATTGGCAATGAGCGGTTCCGC-3' and reverse 5'-CTCCTGCTTGCTGATCCACATC-3'). All samples and reagents were mixed and incubated 
using Eco Real-Time PCR System at $95^{\circ} \mathrm{C}$ for $3 \mathrm{~min}$, followed by 40 cycles of $95^{\circ} \mathrm{C}$ for $10 \mathrm{~s}$ and $60^{\circ} \mathrm{C}$ for $1 \mathrm{~min}$. The mRNA expression analysis was performed using Eco Study Software (Illumina Inc., San Diego CA, USA).

\section{Statistical analysis}

All data are displayed as means \pm standard deviation. The data calculation was employed using SPSS 23.0 (IBM Corp., NY, USA). The difference statistical significances between groups were calculated using one-way ANOVA, followed by Bonferroni post hoc analysis. $p<0.05$ was considered significant.

\section{Results}

\section{Measurement of rats' blood glucose and body weight}

The final weight of STZ-induced diabetic rats on the control groups was markedly lower than normal rats. The blood glucose level of all diabetic rats was totally higher compared to sham. After MSCs administration, the final weight of the T1 and T2 was significantly higher than the control $(p=0.0413$ for T1 and $p=0.0309$ for T2). On the other hand, the final blood glucose level of the T1 and T2 groups was also significantly lower than control $(p=0.0192$ for T1 and $\mathrm{p}=0.0079$ for T2; Table 1).

Table 1: Bodyweight and blood glucose variable

\begin{tabular}{lllll}
\hline Variable & Sham & Control & T1 & T2 \\
\hline Initial weight $(\mathrm{g})$ & $213.6 \pm 13.8$ & $208.8 \pm 12.2$ & $209.6 \pm 13.0$ & $211.8 \pm 10.3$ \\
Final weight $(\mathrm{g})$ & $346.6 \pm 29.3^{*}$ & $194.2 \pm 8.2$ & $231.6 \pm 22.4^{*}$ & $293.8 \pm 7.3^{*}$ \\
Initial glucose $(\mathrm{mg} / \mathrm{dL})$ & $170.2 \pm 11.9$ & $156.8 \pm 10.5$ & $164.7 \pm 12.4$ & $174.7 \pm 8.6$ \\
Final glucose $(\mathrm{mg} / \mathrm{dL})$ & $140.2 \pm 25.9^{*}$ & $512.8 \pm 47.2$ & $431.4 \pm 27.0^{*}$ & $265.4 \pm 64.0^{*}$ \\
\hline \multicolumn{4}{l}{ Values are expressed as mean $\pm \mathrm{SD}{ }^{*}<0.05$ compared to the control group. SD: Standard } \\
deviation $\mathrm{n}=$ 6/group.
\end{tabular}
deviation. $n=6 /$ group.

\section{Characteristics and differentiation capability of MSCs}

MSCs from the UC were analyzed for plasticadherent potential under standard culture conditions, antigen-specific surface markers, and differentiation capability after four passages. In this study, the MSCs morphology at the fourth passage exhibited specific monolayers of spindle fibroblast-like and adherent capacity to the plastic culture (Figure 1a). The osteogenic and adipogenic differentiation capability of MSCs was analyzed by culturing the MSCs under osteogenic and adipogenic differentiation medium for 21 and 30 days, respectively. After incubation, the calcium and adipose deposition were visualized as a red color after alizarin red and oil red o solution administration, respectively (Figure $1 \mathrm{~b}$ and $\mathrm{c}$ ). On the other hand, to characterize MSCs surface antigens, we performed flow cytometry analysis regarding the International Society for Cellular Therapy. We found a high level of CD90.1 (99.3 $\pm 0.54 \%)$ and CD29 (95.2 $\pm 0.73 \%)$ and negative

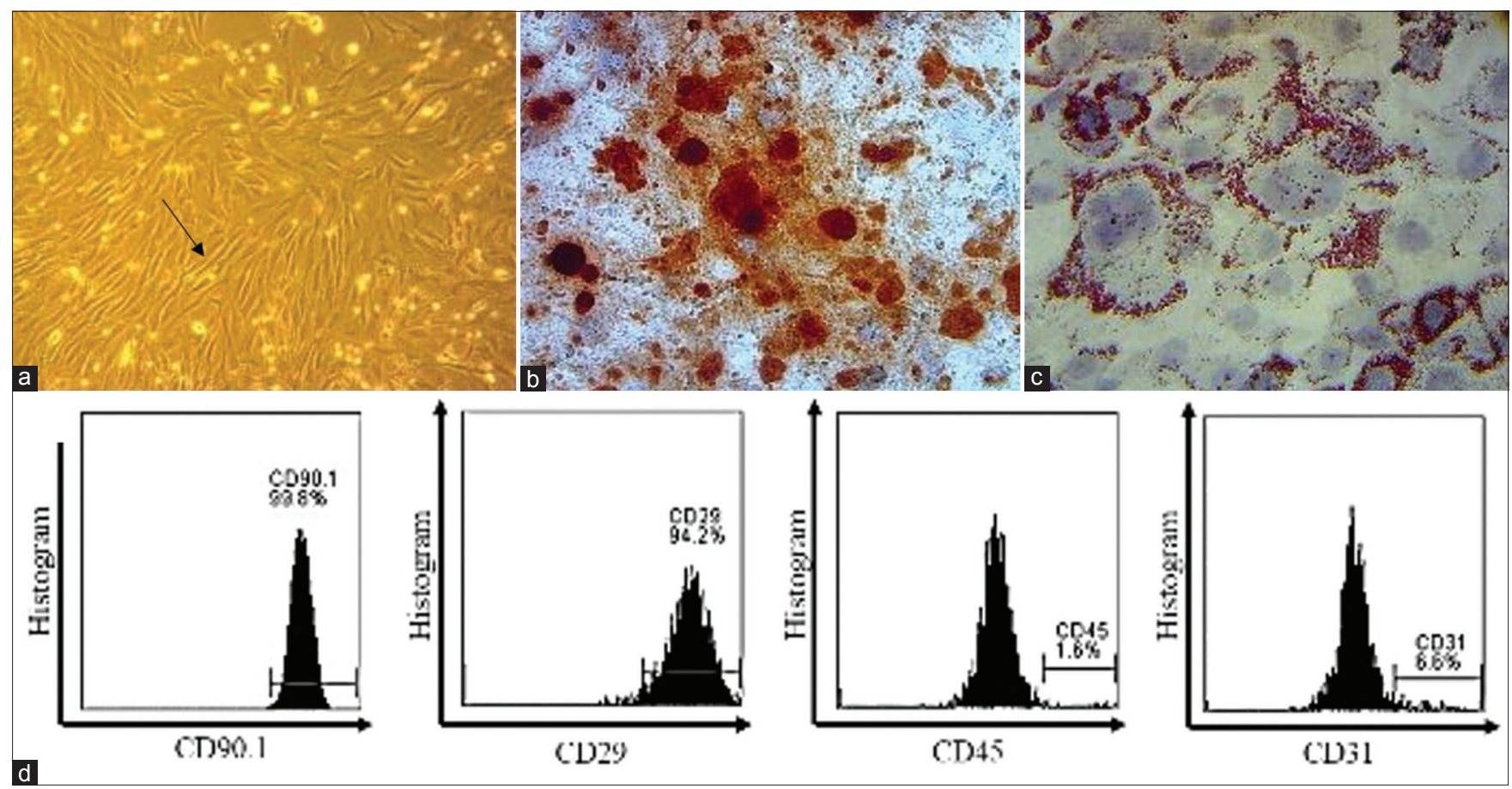

Figure 1: Mesenchymal stem cell (MSCs) candidates showed spindle forms such as fibroblast-like cells (100x magnification) (a). MSCs were incubated by osteogenic and adipogenic differentiation medium to evaluate the capability of MSCs to differentiate into osteocyte and adipocyte, respectively. The calcium deposits were positively stained and represented in red color after alizarin red staining (b), and the adipose deposition was also represented in red color after oil red staining (c). MSCs also expressed CD90.1, CD29, and lacked the expression of $C D 31$ and $C D 45$ after flow cytometry analysis (d) 
expression of CD31 (5.62 $\pm 1.27 \%)$ and CD45 (1.66 $\pm 0.24 \%$; Figure 1d).

\section{MSCs enhance the erectile function of} DMED rat models

Erectile function measurement showed that DMED induction decreased erectile response significantly in rats. After administration of MSCs, the erectile response experienced a significant increase compared to the control group $(0.33 \pm 0.52)$, where the erectile response in the T1 group was $19.67 \pm 1.63$ $(p=0.0021)$ and the T2 group was $25 \pm 2.45(p=0.0014)$ within $30 \mathrm{~min}$. Whereas, the erection response of the sham group was $6.83 \pm 0.75(p=0.0093)$. In which the fastest recovery was on the T2 with a value of (Figure 2 ).

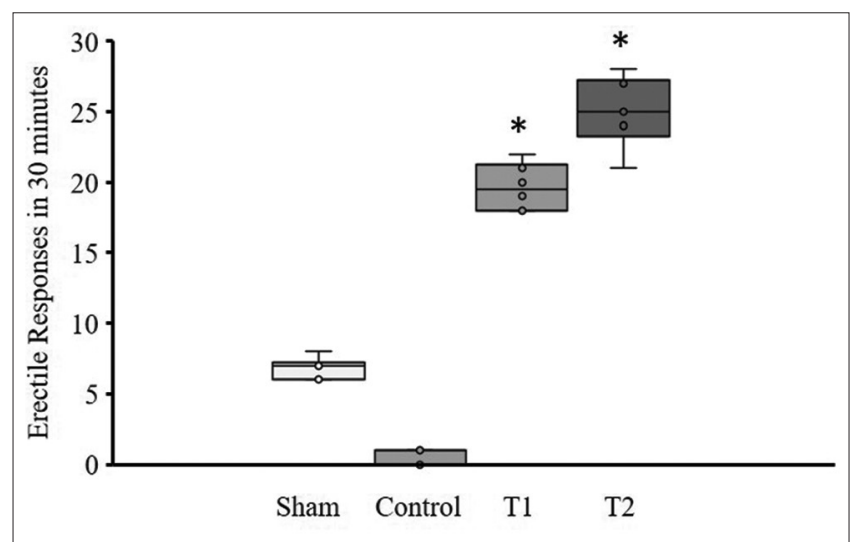

Figure 2: Erectile function measurement in rats with diabetes mellitus erectile dysfunction (DMED) in each group ( $n=6 /$ group). Graph summarizing the quantitative data of erectile responses DMED rats in 30 min and expressed as mean \pm standard deviation. ${ }^{*} p<0.05$ compared with control group

\section{MSCs administration increases eNOS} expressions in corpus cavernosum tissue

$\mathrm{IHC}$ results showed that the DMED induction in rats caused a significant decrease in the expression of eNOS in corpus cavernosum tissue $(p=0.0273)$. After

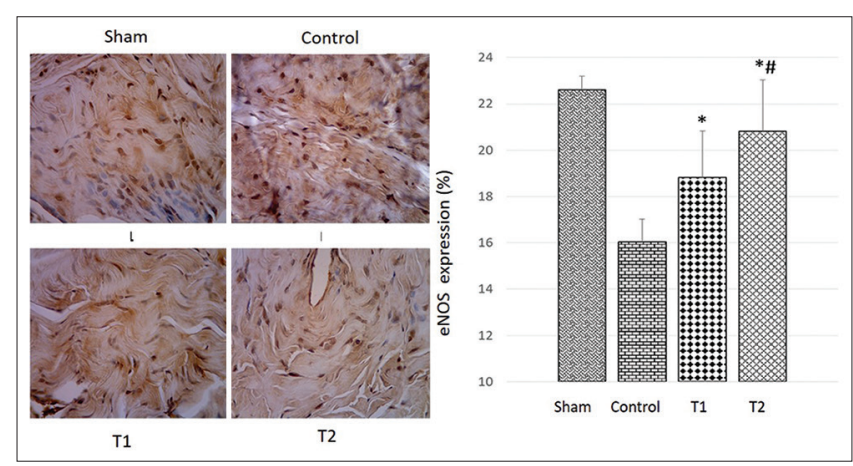

Figure 3: eNOS expression in corpus cavernosum tissue from each group ( $n=6 /$ group). Representative images of eNOS expression in the corpus cavernosum tissue original magnification: $\times 400$. Graph summarizing the quantitative data of eNOS content in corpus cavernosum tissue and expressed as mean \pm standard deviation. ${ }^{*} p<0.05$ compared with control
MSCs administration, rats on $\mathrm{T} 1$ showed a partial recovery of eNOS expression $(p=0.0467)$. The T2 group showed an optimum recovery of eNOS, in which the value of eNOS expression was $20.66 \pm 2.32 \%$ (Figure $3 a$ and $b$ ).

\section{MSCs administration decrease HSP70 expression in corpus cavernosum tissue}

IHC results showed that the DMED induction in rats caused a significant increase in the expression of HSP70 in corpus cavernosum tissue $(p=0.0402)$. After MSCs administration, rats on T1 showed a significant decrease of HSP70 expression $(p=0.0110)$. Moreover, the T2 showed an optimum decrease of HSP70 content, in which the value of HSP70 expression was $15.50 \pm 0.90 \%$ (Figure $4 a$ and $b$ ).

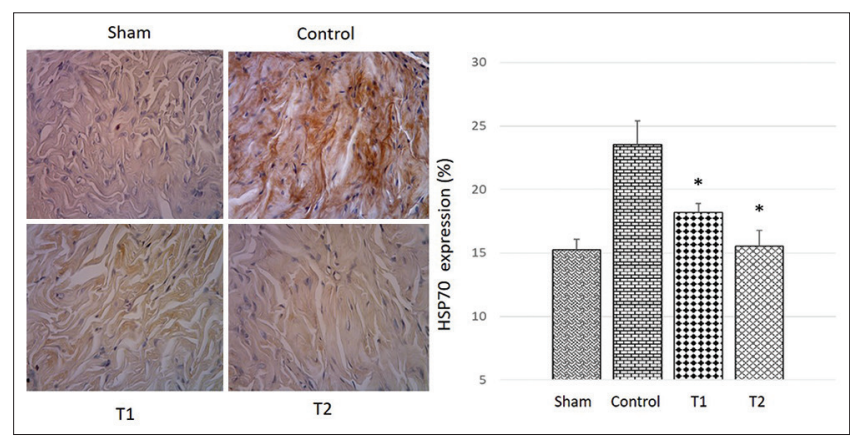

Figure 4: HSP-70 expression in corpus cavernosum tissue from each group ( $n=6 /$ group). Representative images of HSP-70 expression in the corpus cavernosum tissue original magnification: $\times 400$. Graph summarizing the quantitative data of HSP-70 content in corpus cavernosum tissue and expressed as mean \pm standard deviation. ${ }^{*} p<0.05$ compared with control

\section{MSCs administration increases VEGF-A} mRNA level in corpus cavernosum tissue

qRT-PCR results showed that the DMED induction in rats caused a significant decrease of VEGF-A mRNA content in corpus cavernosum tissue $(p=0.0364)$. After MSCs administration, rats on the T1 showed a trend of increase of VEGF-A mRNA level expression. Moreover, the T2 showed an optimum significant increase of VEGF-A mRNA level content, in which the value of VEGF-A mRNA level was $2.2 \pm 0.61(p=0.0092$; Figure 5$)$.

\section{Discussion}

DMED is a complex vascular disease characterized by prolonged hyperglycemia on the corpus cavernosum, nerves, and blood vessels, and the dysfunction of the endothelium, leading to penile fibrosis. These severe and complex mechanisms can damage the corpus cavernosum structure, leading to decreased erectile function [22]. A previous study reported that VEGF-A expression and signaling 


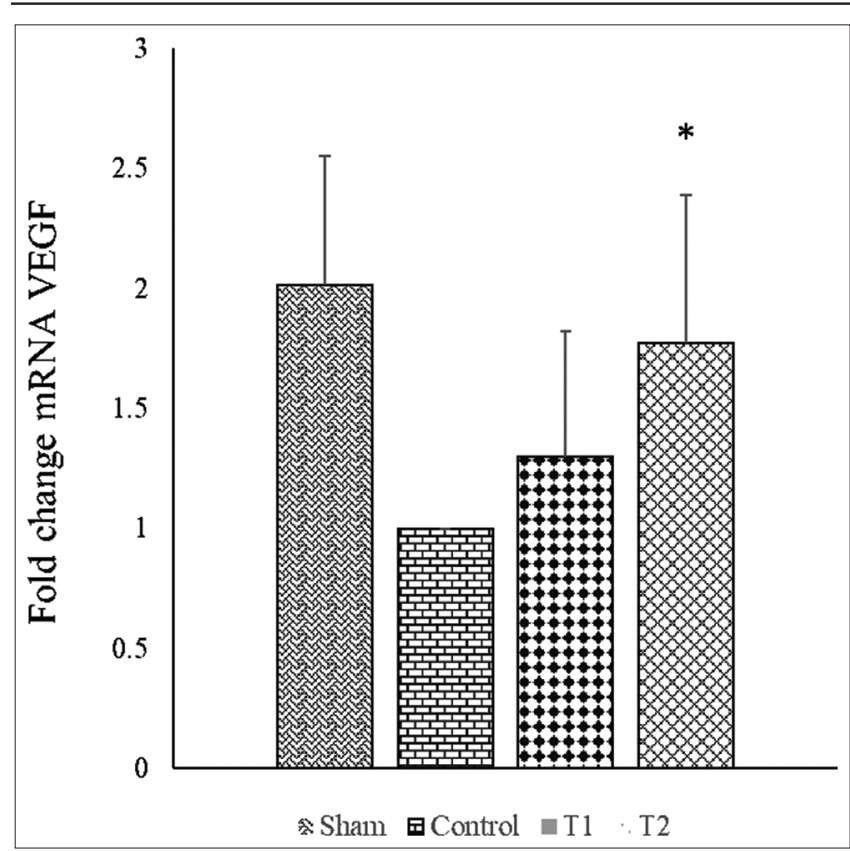

Figure 5: mRNA level of VEGF-A in corpus cavernosum tissue from each group ( $n=6 /$ group). Graph summarizing the quantitative data of VEGF-A mRNA level in corpus cavernosum tissue and expressed as mean \pm standard deviation. ${ }^{*} p<0.05$ compared with control

molecules such as eNOS and NO were decreases in the penile tissue of STZ-induced diabetic rats [2]. On another side, a previous study revealed that chronic hyperglycemia and DM lead to decreased production and activity of NO [16]. NO is established through the L-arginine alteration by NOS, which results in three isoforms: iNOS, nNOS, and eNOS; respectively [16]. In the DMED condition, eNOS was expressed in the smooth muscle cells and cavernosal endothelium, which appeared to be fundamental for erectile function maintenance [23].

In this study, the MSCs treatment of all treatment groups increased the expression of eNOS in DMED rats, in which the T2 group has an optimum enhancement. These results also supported another finding, which reported that the MSCs in all treatment groups could enhance the mRNA VEGF-A expression in penile tissues. The T2 group has optimum expression. These findings suggest that MSCs treatment was effective in promoting the revascularization of corpus cavernosum on DMED rats. A previous study revealed that $p$-AKT could stimulate endothelial cells to express eNOS, crucial for vasodilatation [15]. The significant enhancement of the level of eNOS in the corpus cavernosum on all treatment groups than control suggested that MSCs could enhance the expression of VEGF-A in the corpus cavernosum to trigger the PI3KAKT signaling pathway, resulting in the enhancement of eNOS expression. The increase of eNOS could inhibit vasospasm and stimulate the vasodilatation process, thereby restore the blood supply and improve DMED [15]

The previous studies revealed that the improvement of cellular repair could be characterized by cellular stress levels, such as HSP70 [18]. On the other hand, other studies revealed that endothelial cells avenge with an anti-inflammatory response by producing antioxidant and cytoprotective protein, resulting in the expression of HSP70 [23]. Moreover, another study also reported that HSP70 is essential for angiogenesis through activation of p-Akt signaling in which the inhibition of HSP70 level could decrease the activation of p-Akt [15]. Interestingly, our findings showed that MSCs in all treatment groups decreased the expression of HSP70 in the corpus cavernosum, besides the control group showed an increased level of HSP70. MSCs attenuate the inflammatory condition by expressing several anti-inflammatory molecules [9] and decrease the expression of HSP70 in treatment groups into normal conditions. These conditions could lead to the expression of VEGF-A that promotes vascularization in the corpus cavernosum.

Our experiment does have some places for improvement. In this study, we just performed an animal experiment. We did not analyze the expression of the p-Akt pathway and its blockade mechanism in vitro. We also did not analyze the number of blood vessels in the corpus cavernosum.

\section{Conclusion}

MSCs could increase the level of eNOS and VEGF-A levels in DMED induction rats. Therefore, MSCs also reduced the HSP70 level associated with enhancing the erectile function of DMED rat models. This MSCs capacity could become an attractive and great therapy to improve erectile function in diabetic patients.

\section{Acknowledgments}

The authors acknowledge that this study is supported by the Universitas Sumatera Utara and Stem Cell and Cancer Research Indonesia. We thank all people who contributed to this research.

\section{References}

1. Kouidrat $Y$, Pizzol D, Cosco T, Thompson T, Carnaghi M, Bertoldo $A$, et al. High prevalence of erectile dysfunction in diabetes: A systematic review and meta-analysis of 145 studies. Diabet Med. 2017;34(9):1185-92. https://doi.org/10.1111/ dme.13403

PMid:28722225 
2. Qiu $X$, Sun $C$, Yu W, Lin H, Sun Z, Chen $Y$, et al. Combined strategy of mesenchymal stem cell injection with vascular endothelial growth factor gene therapy for the treatment of diabetes-associated erectile dysfunction. J Androl. 2012;33(1):37-44. https://doi.org/10.2164/jandrol.110.012666 PMid:21311050

3. Davies KP. Development and therapeutic applications of nitric oxide-releasing materials. Future Sci OA. 2015;1(1):FSO50. https://doi.org/10.4155/FSO.15.50

PMid:28031864

4. Chen S, Zhu J, Wang M, Huang Y, Qiu Z, Li J, et al. Comparison of the therapeutic effects of adipose-derived and bone marrow mesenchymal stem cells on erectile dysfunction in diabetic rats. Int J Mol Med. 2019;44(3):1006-14. https://doi.org/10.3892/ ijmm.2019.4254

PMid:31257465

5. Jin H, Kim WJ, Song JS, Choi MJ, Piao S, Shin SH, et al. Functional and morphologic characterizations of the diabetic mouse corpus cavernosum: Comparison of a multiple low-dose and a single high-dose streptozotocin protocols. J Sex Med. 2009;6(12):3289-304. https://doi. org/10.1111/j.1743-6109.2009.01464.x

PMid:19732306

6. Zhang Y, Chen Z, Wang T, Yang J, LiR, Wang S, et al. Treatment of diabetes mellitus-induced erectile dysfunction using endothelial progenitor cells genetically modified with human telomerase reverse transcriptase. Oncotarget. 2016;7(26):39302-15. https://doi.org/10.18632/oncotarget.9909

PMid:27283992

7. Wang $\mathrm{H}$, Zhang $\mathrm{K}$, Ruan $\mathrm{Z}$, Sun $\mathrm{D}$, Zhang $\mathrm{H}$, Lin $\mathrm{G}$, et al Probucol enhances the therapeutic efficiency of mesenchymal stem cells in the treatment of erectile dysfunction in diabetic rats by prolonging their survival time via Nrf2 pathway. Stem Cell Res Ther. 2020;11(1):302. https://doi.org/10.1186/ s13287-020-01788-3

PMid:32693824

8. Kim SW, Zhu GQ, Bae WJ. Mesenchymal stem cells treatment for erectile dysfunction in diabetic rats. Sex Med Rev. 2020;8(1):114-21. https://doi.org/10.1016/j.sxmr.2019.09.003 PMid:31653438

9. Putra A, Rosdiana I, Darlan DM, Alif I, Hayuningtyas F, Wijaya I, et al. Intravenous administration is the best route of mesenchymal stem cells migration in improving liver function enzyme of acute liver failure. Folia Med (Plovdiv). 2020;62(1):52-8. https://doi. org/10.3897/folmed.e47712

PMid:32337897

10. Sungkar T, Putra A, Lindarto D, Sembiring RJ. Intravenous umbilical cord-derived mesenchymal stem cells transplantation regulates hyaluronic acid and interleukin-10 secretion producing low-grade liver fibrosis in experimental rat. Med Arch. 2020;74(3):177-82. https://doi.org/10.5455/ medarh.2020.74.177-182 PMid:32801431

11. Bae JH, Shrestha KR, Park YH, Kim IG, Piao S, Jung AR, et al. Comparison between subcutaneous injection of basic fibroblast growth factor-hydrogel and intracavernous injection of adiposederived stem cells in a rat model of cavernous nerve injury. Urology. 2014;84(5):1248.e1-7. https://doi.org/10.1016/j.urology.2014.07.028 PMid:25443945

12. Darlan DM, Munir D, Jusuf NK, Putra A, Ikhsan R, Alif I. In vitro regulation of IL- 6 and TGF- $\beta$ by mesenchymal stem cells in systemic lupus erythematosus patients. Med Glas (Zenica). 2020;17(2):408-13. https://doi.org/10.17392/1186-20 PMid:32602296

13. Putra A, Pertiwi D, Milla MN, Indrayani UD, Jannah D, Sahariyan $M$, et al. Hypoxia-preconditioned MSCs have superior effect in ameliorating renal function on acute renal failure animal model. Open Access Maced J Med Sci. 2019;7(3):305-10. https://doi. org/10.3889/oamjms.2019.049 PMid:30833992

14. Marino L, Castaldi MA, Rosamilio R, Ragni E, Vitolo R, Fulgione $C$, et al. Mesenchymal stem cells from the Wharton's jelly of the human umbilical cord: Biological properties and therapeutic potential. Int J Stem Cells. 2019;12(2):218-26. https://doi.org/10.15283/ijsc18034 PMid:31022994

15. Maron BA, Michel T. Subcellular localization of oxidants and redox modulation of endothelial nitric oxide synthase. Circ J. 2012;76(11):2497-512. https://doi.org/10.1253/circj.cj-12-1207 PMid:23075817

16. Jeon SH, Zhu GQ, Bae WJ, Choi SW, Jeong HC, Cho HJ, et al. Engineered mesenchymal stem cells expressing stromal cellderived factor-1 improve erectile dysfunction in streptozotocininduced diabetic rats. Int J Mol Sci. 2018;19(12):3730. https:// doi.org/10.3390/ijms19123730

PMid:30477146

17. Zhou $F$, Hui $Y$, Xin $H, X u Y$ De, Lei HE, Yang BC, et al. Therapeutic effects of adipose-derived stem cells-based microtissues on erectile dysfunction in streptozotocin-induced diabetic rats. Asian J Androl. 2017;19(1):91-7. https://doi. org/10.4103/1008-682X.182817 PMid:27345005

18. Li T, Liu Y, Yu L, Lao J, Zhang M, Jin J, et al. Human umbilical cord mesenchymal stem cells protect against SCA3 by modulating the level of $70 \mathrm{kD}$ heat shock protein. Cell Mol Neurobiol. 2018;38(3):641-55. https://doi.org/10.1007/s10571-017-0513-1 PMid:28667374

19. Madrigal M, Rao KS, Riordan NH. A review of therapeutic effects of mesenchymal stem cell secretions and induction of secretory modification by different culture methods. J Transl Med. 2014;12(1):260. https://doi.org/10.1186/s12967-014-0260-8 PMid:25304688

20. FioriA, Terlizzi V, KremerH, Gebauer J, Hammes HP, Harmsen MC et al. Mesenchymal stromal/stem cells as potential therapy in diabetic retinopathy. Immunobiology. 2018;223(12):729-43 https://doi.org/10.1016/j.imbio.2018.01.001. PMid:29402461

21. Heaton JP, Varrin SJ, MoralesA. The characterization of a bio-assay of erectile function in a rat model. J Urol. 1991;145(5):1099-102. https://doi.org/10.1016/s0022-5347(17)38543-9 PMid:2016801

22. Wu Z, Wang $\mathrm{H}, \mathrm{Ni} F$, Jiang $\mathrm{X}, \mathrm{Xu} \mathrm{Z}$, Liu $\mathrm{C}$, et al. Islet transplantation improved penile tissue fibrosis in a rat model of Type 1 diabetes. BMC Endocr Disord. 2018;18(1):49. https:// doi.org/10.1186/s12902-018-0276-9

23. Costa-Beber LC, Hirsch GE, Heck TG, Ludwig MS. Chaperone duality: The role of extracellular and intracellular HSP70 as a biomarker of endothelial dysfunction in the development of atherosclerosis. Arch Physiol Biochem. 2020:1-8. https://doi.org /10.1080/13813455.2020.1745850

PMid:32293198 